\title{
PARTIAL DISCHARGE MEASUREMENT IN IMPREFECTIONS OF OIL-PAPER INSULATING SYSTEMS
}

\author{
SIRUCEK, M[artin]; PASLAVSKY, B[ohumil]; TRNKA, P[avel] \& PIHERA, J[osef]
}

\begin{abstract}
The paper deals with partial discharges (PD) measurement of oil-paper insulating system. This system is usually used in bushings, power cables and power transformers. The experiment consists of two parts. The first part is PD measurement of oil-paper samples represent transformer winding insulation. They were composed of a small copper bar overlapped by a transformer paper. In the paper insulation the two types of non-homogenous areas were created. The second part of the experiment was focused on statistical evaluation of ignition voltages in these areas. PD measurement were realised in mineral and environmentally friendly oil.
\end{abstract}

Key words: partial discharges, ignition voltage, normal distribution, oil-paper insulating system

\section{INTRODUCTION}

Partial discharges measurement has been used about 60 years as an important diagnostics method of high voltage machines. This method is used for detection of non-homogenous areas, failures and defects in insulating systems. These imperfections of the system are created by technology process faultinesses or thermal, electrical and mechanical stress during transformer running condition. These defects are usually represented by gas voids. A voltage on defect causes ionization of gas. It leads to small breakdowns within the voids. Partial discharges can contain sufficient energy for hydrocarbon strings dissociation and degradation of insulation system parts occurs. These activities are usually measured in windings, coils and bushings. Partial discharge activity is usually compared with phase of the test voltage. The main parameters are ignition voltage, extinguish voltage, pulse count, average discharge current and apparent charge.

This paper is focused on the partial discharge measurement in non-homogenous areas with different dimension in the oil paper insulating system. The experiment is the beginning of a new series of experiments focused on the study of partial discharges in different imperfection in the oil-paper insulating system. Study of partial discharge activities vs. phase can show a type of irregularities and accurately to determine the causes of the disorder. PD measurement in different environments and different arrangement of electrodes was observed (Zhou Quan et al., 2010). On oil-paper insulation system are focused authors (Cavallini et al., 2005) and (Chen et al., 2009) but not on the overlap imperfection. Statistical evaluation on stage of thermal aged oil-paper insulation was determined (Jian Li et al., 2006). The Normal distribution of ignition voltage values is accurate method which provided important information about part of insulation because respect values dispersion.

\section{EXPERIMENT}

The aim of the experiment was to study changes of discharge activities in the areas with different sizes of not-regularly overlapped insulating material. Irregularities may cause uneven distribution of electric potential and partial discharges occur. The aim of the experiment was to proof that a small irregularity causes a high partial discharge activity and reversely a large imperfection causes only small one. The test sample was a copper bar wrapped by two layers of kraft paper 22 HCC Dennison. Four samples were tested in mineral oil DIALA DX and environmentally friendly oil FR3 too. The different types of irregularities were created in the solid insulation. The measured arrangements were symmetrical insulation and not-regularly overlapped insulation with dimension 3-4 mm (Type A) and 1$2 \mathrm{~mm}$ (Type B).

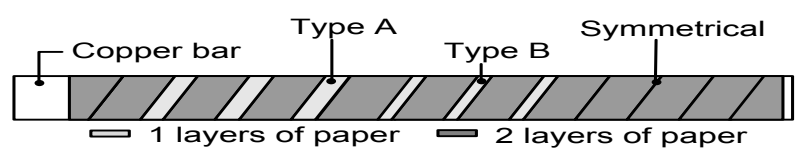

Fig. 1. Sample arrangement

For each electrode 15 values of ignition voltages (IV) were measured. The next parameter was values of the apparent charge (Qiec) for 1. and 10. minutes. Measurements were preformed for higher tested voltages too. Its values were approximately 1.25 times higher than IV of the area. Equipment Doble Lemke PD Smart (the test setup shows Fig. 2) was used for directional sensing of PD pulses throw coupling capacitor. Data measured in frequency range $100 \mathrm{kHz} \div 500 \mathrm{kHz}$ accorded to IEC 60270 were analyzed by PC evaluation unit.

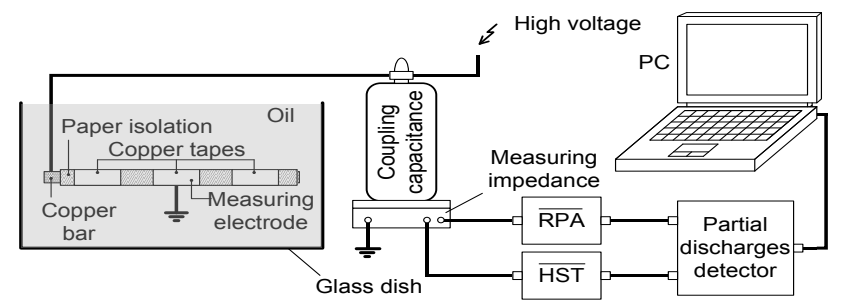

Fig. 2. Test setup

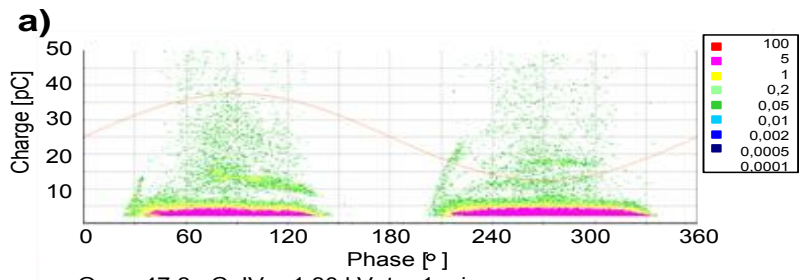

b) $\mathrm{Q}_{\mathrm{iec}}=47,3 \mathrm{pC}, \mathrm{IV}=1,30 \mathrm{kV}, \mathrm{t}=1 \mathrm{~min}$

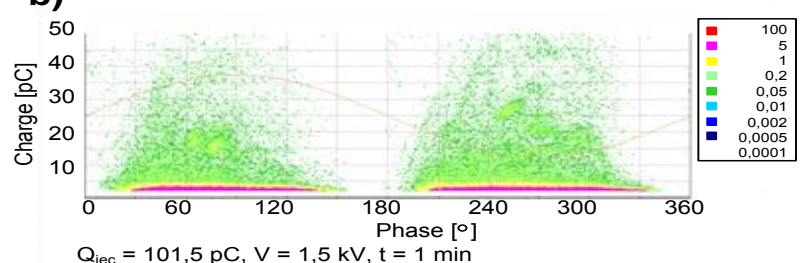

Fig. 3. PD pattern of Type B of insulation arragement 


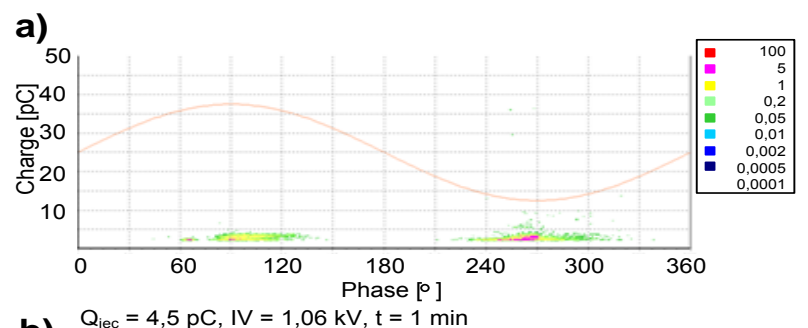

b) $\mathrm{Q}_{\mathrm{iec}}=4,5 \mathrm{pC}, \mathrm{IV}=1,06 \mathrm{kV}, \mathrm{t}=1 \mathrm{~min}$

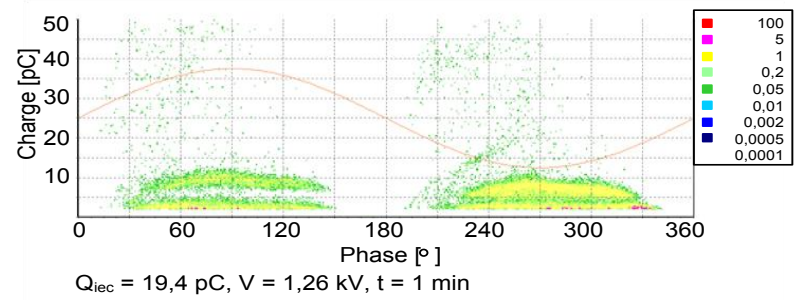

Fig. 4. PD pattern of Type B of insulation arragement

Results of PD measurement are shown in Fig. 3 (Type B) and Fig. 4 (Type A). Values of Qiec significantly depend on the testing voltage. The Qiec of imperfection areas were about $5 \div$ $290 \mathrm{pC}$ in DIALA and $10 \div 320 \mathrm{pC}$ in FR3. The symmetrical insulation values were approximately $8 \div 130 \mathrm{pC}$ in DIALA and $3 \div 140 \mathrm{pC}$ for FR3

\section{STATISTICAL EVALUATION}

Right values of measured quantities $\mathrm{x}$ is difficult to detect from measured data. Set of measured numbers is used for calculation of average value and adequate accuracy. This requirement is satisfied by the interval size depend on values, number of measurement and their dispersion. Fifteen inception voltages of all samples tested in the first experiment were measured. The normal distribution $\mathbf{N}$ was used for their evaluation. In Formula 1 is shown equation of this distribution with two base parameters.

$$
N(\bar{x}, \sigma)=f(x)=\frac{1}{\sigma \sqrt{2 \pi}} e^{-\left(x_{i}-x\right)^{2} / 2 \sigma^{2}}
$$

The first is arithmetic mean $\overline{\mathbf{x}}$ is defined as rate of total measured values and number of values. The second is standard deviation $\sigma$. The right value lays in this distribution in interval $\pm \sigma$ from $\overline{\mathbf{x}}$ with probability $68.2 \%$, for $\pm 2 \sigma$ is probability $95.4 \%$ and for $\pm 3 \sigma$ is $99.6 \%$. Fifteen measurement of ignition voltage for each electrode was done. Calculated values are affected by one or two outlying measured values. They are probably cause for example very fast regulation of the applied voltage, or lack of recovery of the insulation system during the measurement of two consecutive values. Therefore from the data two distant values were removed by application of modified internal walls method (Meloun \& Militky, 2002).

Measured data from all electrodes are divided to three groups. The first has IV values from $0.4 \mathrm{kV}$ up to $0.7 \mathrm{kV}$. The second group has IV values around $1 \mathrm{kV}$ and the last has IV values higher than $1.3 \mathrm{kV}$. Each of these groups is approximately equal to the type of measured areas. In the Fig. 5 is shown example of the normal distribution one of these groups. First sign in the legend is type of the oil, second a sample number and last electrode position (Type A (3), Type B (2), sym. (1)). In the Fig.6 is shown normal distribution of IV for each arrangement of paper insulation in both oils. In the symmetrical insulation areas were found the highest values of IV (mineral oil $1.2 \mathrm{kV}$ and FR3 1.6 kV). Probably smaller recovery abilities of FR3 are reason for this. In areas with imperfection were ignition voltage values significantly lower.

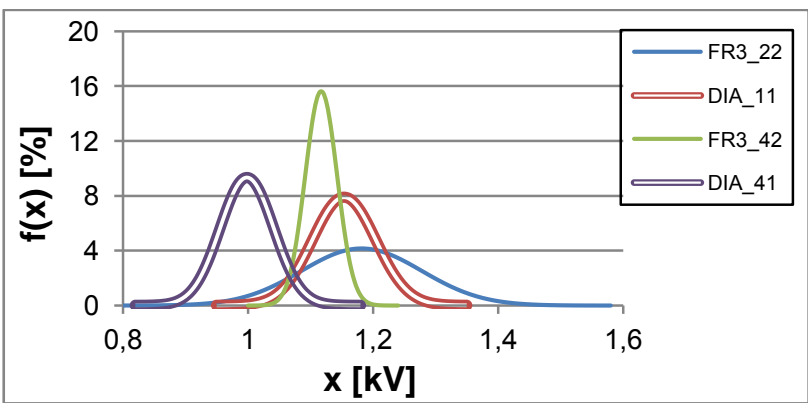

Fig. 5. Normal distribution of the $1 \mathrm{kV}$ IV group

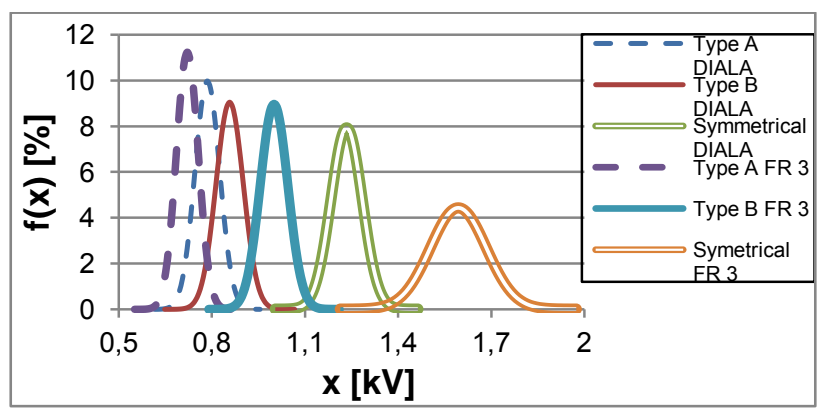

Fig. 6. Normal Distribution of IV of all insulation arrangements in both oils

\section{CONCLUSION}

Results show that dimensions of not-overlap areas in both oils have important influence especially on ignition voltages (IV). The discharge activities are depending on gaps geometry within the insulation and an insulation system quality. Therefore is necessary ensuring of suitable drying and winding in preparation of the sample. Hypothesis that a large imperfection can produce a small discharge activity was confirmed.

\section{ACKNOWLEDGEMENTS}

This research was funded by the Ministry of Education, Youth and Sports of the Czech Republic, MSM 4977751310 Diagnostics of Interactive Processes in Electrical Engineering. The authors are grateful for the support of this program.

\section{REFERENCES}

Cavallini, A.; Montanari, G.C. \& Ciani, F. (2005). Analysis of partial discharge phenomena in paper-oil insulation systems as a basis for risk assessment evaluation, Dielectric Liquids, 2005. ICDL 2005. 2005 IEEE International Conference on, pp. 241-244, 26 June-1 July 2005

Chen, X.; Cavallini, A. \& Montanari, G.C. (2009). Statistical analysis and fuzzy logic identification of partial discharge in paper-oil insulation system, Properties and Applications of Dielectric Materials, 2009. ICPADM 2009. IEEE 9th International Conference on the, pp.505-508, 19-23 July 2009

Jian Li; Grzybowski, S.; Lijun Yang \& Ruijin Liao. (2006). Statistical Parameters of Partial Discharge Used to Recognize Aged Oil-Paper Insulation, Power Modulator Symposium, 2006. Conference Record of the 2006 TwentySeventh International, pp. 75 - 80, 14-18 May 2006

Meloun, M. \& Militky, J. (2002). Compendium of Statistical Data Elaboration, Academia Praha, ISBN 80-200-1396-2

Zhou Quan; Zhang Yun; An Wen-dou; Liu Fan; Liao Rui-jin \& Zhang Xin (2010). PD pattern recognition in oil-paper insulation based on discharge time interval, High Voltage Engineering and Application, 2010. ICHVE 2010. International Conference on the, pp. 313 - 316, 11-14 Oct. 2010 